\title{
Acute Subdural Hematoma Complicating Treatment with Anti-Vitamin K
} DIAI Abdellatif ${ }^{1,3^{*}}$, MAAROUFI Ayoub ${ }^{1,3}$, JEBBAR Nourddine ${ }^{1,3}$, ELKAISSI Jaber ${ }^{1,3}$, Hicham Kechna ${ }^{1,3}$, LAOUTID Jaouad ${ }^{1,3}$ Khalil Mounir $^{2}$

${ }^{1}$ Anesthesiology \&amp; intensive care Department, Moulay Ismail Military Hospital, Meknes, Morocco

${ }^{2}$ Anesthesiology \&amp; intensive care Department, Military Hospital Mohamed V, RABAT, Morocco

${ }^{3}$ Faculty of Medicine, Sidi Mohamed Ben Abdellah University, Fes, Morocco

DOI: $10.36347 /$ sasjm.2021.v07i02.003 $\quad$ | Received: 25.01 .2021 | Accepted: 16.02 .2021 | Published: 18.02 .2021

*Corresponding author: Diai Abdellatif

One of the complications of long-term oral anticoagulation is acute subdural hematoma. The high prevalence of cardiovascular disease in an increasingly older population explains the increasing number of patients on Anti-Vitamin $\mathrm{K}(\mathrm{AVK})$. The use of vitamin $\mathrm{k}$, fresh frozen plasma in the absence of Prothombin Complex Concentrate (PPSB) in the case of intracranial hematomas, is recommended if surgery is to be performed in extreme emergency. Delayed surgery for these patients increases mortality.

Keywords: Subdural hematoma; Anti-vitamin K; antagonization; extreme emergency surgery.

Copyright $\odot 2021$ The Author(s): This is an open-access article distributed under the terms of the Creative Commons Attribution 4.0 International License (CC BY-NC 4.0) which permits unrestricted use, distribution, and reproduction in any medium for non-commercial use provided the original author and source are credited.

\section{INTRODUCTION}

A significant increase in the use of antivitamin $\mathrm{K}$ (VKA) has been observed over the last decades. The aging of the population and the frequency of cardiovascular diseases explain the treatment with AVK in Western countries [1]. Despite this, AVK treatment still presents a high percentage of accidents, the most important and most serious of which are hemorrhagic accidents causing a large number of ICU admissions [2, 3]. Subdural hematoma (HSD) is a rarely described event during VKA overdose. We present the case of acute HSD in a patient with valvular heart disease undergoing treatment with VKA.

\section{PATIENT AND OBSERVATION}

60-year-old man admitted to the emergency room at Moulay Ismail Hospital in Meknes, for consciousness disorder. He was diabetic, on oral antibiabetic agents, chronic tobacco user, and valvular heart disease with biological valve prosthesis since
2015 on AVK anticoagulant (SINTROM). He was admitted for consciousness disorder motivated his consultation in the Emergency Department. On arrival in the emergency department, the patient was confused, without fever, and Glasgow score of 13 out of 15 .

Biological examinations on admission showed: PT: 14\%, INR: 5.76, TCA: 72 seconds. The patient received an injection of $10 \mathrm{mg}$ of Vitamin $\mathrm{K}$, at the end of the day there was a deterioration of the state of consciousness with a drop in the Glasgow score to 7-8 out of 15 , the brain scan without injection of contrast product was performed showing : a right temporooccipital subdural hematoma up to $17 \mathrm{~mm}$ thick, compressing the opposite cerebral parenchyma and deviating to the left, the median structures, with engagement under right falcorriel and right temporal, with right ventricular hydrocephalus (Figures 1, 2, 3, 4, 5). 


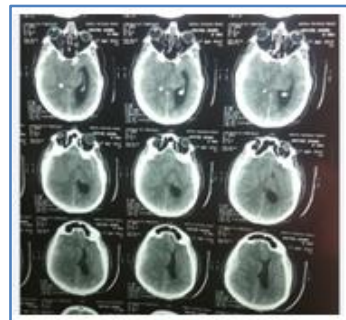

Fig-1

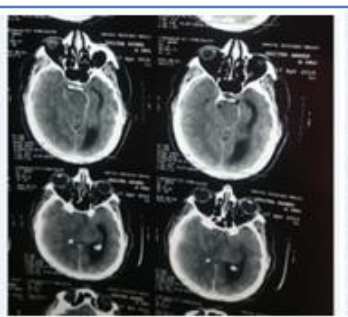

Fig-2

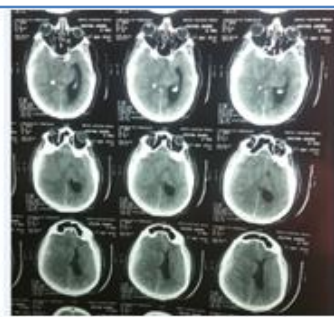

Fig-3

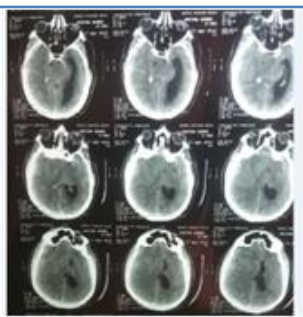

Fig-4

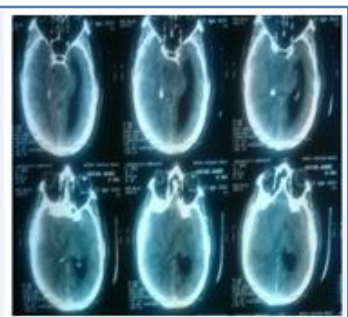

Fig-5
The patient was placed on mechanical ventilation with deep sedation by combining Fentanyl and Midazolam. Admitted to the neurosurgery operating room, the management consisted of a transfusion of fresh frozen plasma (PFC: 9 bags), administration of vitamin $\mathrm{K}$ (Vit $\mathrm{K}$ ) at $10 \mathrm{mg}$, Emergency evacuation of the hematoma was performed with good postoperative CT improvement. (Figures 6, $7,8)$.

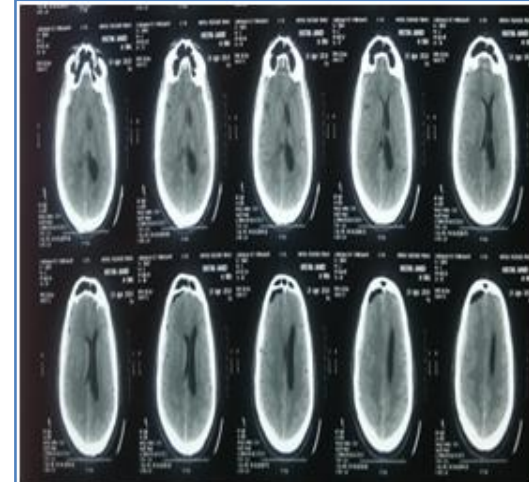

Fig-6

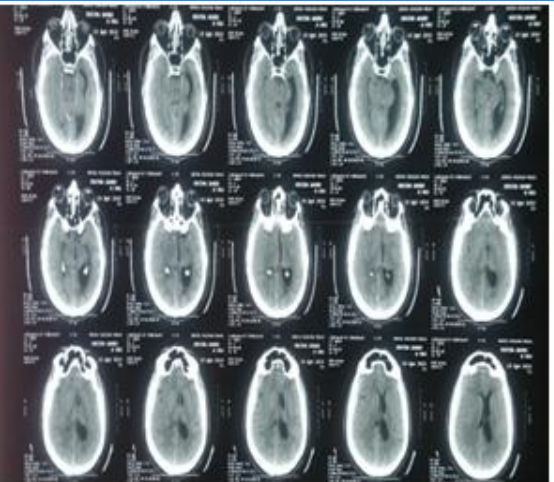

Fig-7

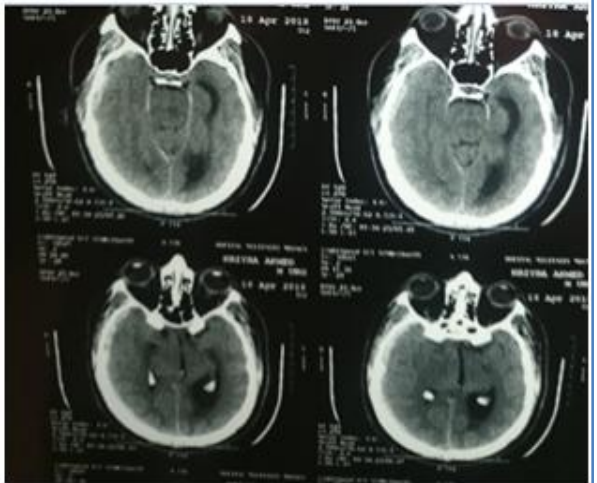

Fig-8
Biological monitoring of the effect of the anticoagulation was systematic, the PT was 37\%, INR 2.11 and the TCA 41.2 seconds, the hemodynamic state was stable. After 24 hours the patient was extubated after cessation of sedation with an improvement of his neurological state on awakening with a GCS at 13-14 / 15 , the patient was transferred to the neurosurgery department 48 hours later.

\section{DISCUSSION}

The annual incidence of severe bleeding events with VKA is estimated to be around 7\% [4]. Treatment with VKA in patients with biological valves is explained by the phenomenon of endothelization, during which the risk of thromboembolism is high and requires treatment with VKA or even the addition of antiplatelet therapy [5].

Anticoagulant drugs including anti-vitamin $\mathrm{K}$ are indicated in the olderly for the prevention of venous thromboembolic disease (MTVE) and arterial emboli during atrial fibrillation (AF) $[3,6]$.

Intracranial haemorrhages (ICB) represent about $10 \%$ of bleeding accidents and almost all fatal hemorrhages, a patient under VKA has an 8 to 10 times higher risk of presenting with HIC [7].

Treatment with VKA is used in many prothrombogenic situations to reduce the risk of thromboembolism, morbidity and mortality. Monitoring treatment with the INR (International Normalized Ratio) is an essential means of avoiding any hemorrhagic or thromboembolic accident. Almost 10\% of the population aged over 80 is on AVK [2].

The risk of ischemic stroke in the olderly is reduced by adding AVK treatment [3]. The risk of haemorrhagic stroke After 70 years is increased by 1.7 to 2.5 after 85 years by overdose of AVK significantly and depending on the number of years [8].

When the INR remains below 4.5, the incidence of spontaneous bleeding complications remains low [9]. The management of intracranial hemorrhages (HIC) under anti-vitamin K (AVK) requires immediate antagonization, the combination of fresh frozen plasma, vitamin $\mathrm{K}$, or vitamin-K dependent factors, is the "gold standard" treatment during Severe, life-threatening hemorrhages, primarily HIC Whether there is an indication for surgery or not [10].

Vitamin-K dependent factors remain superior to plasma concentrates, both in terms of speed and efficacy $[11,12]$. The active form of vitamin $\mathrm{K}$ allows the $\mathrm{C}$-carboxylation of vitamin $\mathrm{K}$ dependent coagulation proteins necessary for their function (factors II, VII, IX and X, proteins C and S). 
A probabilistic dose of $25 \mathrm{IU} / \mathrm{kg}$, or $1 \mathrm{ml} / \mathrm{kg}$, of PPSB combined with $10 \mathrm{mg}$ of vitamin $\mathrm{K}$ immediately allows a lasting reversal of anticoagulation without side effects, in the absence of an INR on admission. The combination of human prothrombin complex (PPSB) -vitamin $\mathrm{K}$ remains ideal in emergencies [13, 14].

The use of PPSB is recommended if the intervention must be performed in extreme emergency at a dosage of $1 \mathrm{IU} / \mathrm{kg}$ of factor IX for an average decrease of 0.15 in INR (or a $1.5 \%$ increase in PT) an INR of less than 1.5 allows surgery to be performed without worsening the risk of bleeding $[15,16]$.

In the absence of PPSB, the use of PFCs for our patient was the conduct. Rapid availability of treatments (PPSB and vitamin K) should be required and INR monitoring is essential immediately after treatment to ensure that coagulation returns to a desirable level (INR <1.5) without delaying the block operative [16]. Taking Vit $\mathrm{K}$ orally is an equally effective alternative to intravenous [16]. Antagonization should be performed as soon as the diagnosis is made and the surgical indication should not be delayed in these patients [17].

\section{CONCLUSION}

Acute HSD is a hemorrhagic complication of treatment with VKA; it is a life-threatening emergency. The speed of management can improve the patient's prognosis, and treatment with a combination of coagulation factors and vitamin $\mathrm{K}$ is a gold standard to ensure correct hemostasis.

The surgery must not be delayed in any way to save the patient. Close monitoring of patients on AVK by an INR within the therapeutic ranges is essential in order to avoid any complications that could be lifethreatening for the patients.

\section{Conflicts of interest}

All authors declare no conflict of interest.

\section{Contributions from authors}

All the authors participated in the management of the patient; all the authors have read and approved the latest version of the manuscript

\section{REFERENCES}

1. Hirsh J. Oral anticoagulant drugs. N Engl J Med. 1991; 324 (26): 1865-75.

2. Agence française de sécurité sanitaire des produits de santé (AFSSAPS). Traitement anticoagulant par antivitamines $\mathrm{K}(\mathrm{AVK})$ améliorer le bon usage et réduire le risque hémorragique des AVK. L'iatrogénie médicamenteuse. Janvier; 2001.
3. Agence Française Sécurité Sanitaire des Produites de Santé (AFSSAPS). Lettre aux prescripteurs. Le bon usage des traitements anticoagulants par antivitamines K (AVK).8 janvier; 2004.

4. Linkins LA, Choi PT, Douketis JD. Clinical impact of bleeding in patients taking oral anticoagulant therapy for venous thromboembolism: a meta-analysis. Ann Intern Med. 2003; 139 (11): 893-900.

5. Heras M, Chesebro JH, Fuster V. High risk of thromboembolism early after bioprosthetic cardiac valve replacement. J Am Coll Cardiol. 1995; 25: 1111-9.

6. Hylek EM. Oral anticoagulants, Pharmacologic issues for use in the elderly. Clin Geriatr Med. 2001; 17: 113.

7. Sjalander A, Engstrom G, Berntorp E, Svensson P. Risk of haemorrhagic stroke in patients with oral anticoagulation compared with the general population. J Intern Med. 2003; 254(5): 434-8.

8. Fang MC, Chang Y, Hylek EM, Rosand J, Greenberg SM, Go AS. Advanced age, antico- agulation intensity, and risk for intracranial hemorrhage among patients taking warfarin for atrial fibrillation. Ann Intern Med. 2004; 141 (10): 745-52

9. Bussey HI. An overview of anticoagulants, antiplatelet agents, and the combination in patients with mechanical heart valves. J Heart Valve Dis. 2004; 13: 319-24.

10. Ansell J, Hirsh J, Poller L, Bussey H, Jacobson A, Hylek E. The pharmacology and management of vitamin K antagonists: the seventh ACCP conference on antithrombotic and thrombolytic therapy. Chest. 2004; 126(3): 204-33.

11. Fredriksson K, Norrving B, Stromblad LG. Emergency reversal of anticoagulation after intracerebral hemorrhage. Stroke. 1992; 23(7): 972-7.

12. Cartmill M, Dolan G, Byrne JL, Byrne PO. Prothrombin complex concentrate for oral anticoagulant reversal in neurosurgical emergencies. Br J Neurosurg. 2000; 14(5): 458-61.

13. Hirsh J, Dalen JE, Anderson DR, Poller L, Bussey H, Ansell J. Oral anticoagulant. Mechanism of action, clinical effectiveness, and optimal therapeutic range. Chest. 1998; 114(5): 445-69.

14. Jack Ansell, Jack Hirsh, Elaine Hylek, Alan Jacobson, Markn Crowther, Gualtiero Palareti. Pharmacology and management from the Vitamin K Agonists. Chest. 2008; 133; 160S-198S.

15. Whitling AM, Bussey HI, Lyons RM. Comparing differents routes and doses of phytonadione for reversing excessive anticoagulation. Arch Intern Med. 1998; 158: 2136-40.

16. Aharon Lubetsky, Hagith Yonath, David Olchovsky, Ronen Loebstein, Hillel Halkin, MD; David Ezra, MD. Comparison of Oral vs Intravenous Phytonadione (Vitamin K1) in Patients with Excessive Anticoagulation. Arch Intern Med. 2003; 163: 2469- 73.

17. Tazarourte K, Tremey B, Vigué B. Neurochirurgie d'urgence et AVK: retarder la chirurgie n'est pas nécessaire. Neurochirurgie. 2009 Dec 1;55(6):H23-8. 